\title{
WORKSHOP MEDIA PEMBELAJARAN MATEMATIKA BERBASIS ICT MGMP MATEMATIKA SMA KABUPATEN TRENGGALEK
}

\author{
Syaiful Hamzah Nasution', Susy Kuspambudi Andaini², Rini Nurhakiki", \\ Hendro Permadi ${ }^{4}$, Slamet ${ }^{5}$ \\ 1,2,3,4,5 Universitas Negeri Malang \\ email: syaiful.hamzah.fmipa@um.ac.id
}

\begin{abstract}
Currently, ICT is widely used in learning. Various mathematical software is often used as a learning medium to help students understand mathematical concepts. One of the most widely used software in learning is GeoGebra. Based on the results of interviews with the head of the Mathematics MGMP of the Trenggalek Regency High School, information was obtained that most of the high school mathematics teachers in the Trenggalek Regency had not used GeoGebra a lot in learning. This makes the reason for the community service (PkM) to be carried out. This PkM activity aims to provide the basis for making mathematics learning media using GeoGebra software. This activity was carried out in three stages: (1) needs analysis, (2) the implementation of face-to-face workshops, and (3) mentoring in making media for learning mathematics using GeoGebra online. Workshop material presented included: (1) GeoGebra software installation, (2) getting to know GeoGebra work area, (3) tools on GeoGebra, (4) creating objects using GeoGebra, (5) introducing sliders, and (6) basic animation in GeoGebra. The results of the implementation of this PkM are: (1) Trenggalek Regency high school mathematics teacher knows GeoGebra software and can do GeoGebra installation, (2) Trenggalek Regency high school mathematics teacher can use GeoGebra, and (3) Trenggalek Regency high school mathematics teacher can make mathematics learning media using GeoGebra.
\end{abstract}

Keywords: GeoGebra, Mathematics Learning Media, Workshop

\section{PENDAHULUAN}

Tugas utama dosen adalah melaksanakan Tridharma yang meliputi pendidikan, penelitian, dan pengabdian. Dalam kaitannya dengan pengabdian dosen mempunyai tugas untuk membantu masyarakat terkait dengan keilmuan yang dimilikinya. Melalui salah satu dharma, yaitu pengabdian, diharapkan dapat memberikan pelayanan mayarakat untuk berperan dalam pengembangan dan peningkatan keprofesionalan masyarakat sesuai dengan bidang keilmuan dosen yang melakukan pengabdian.

Berdasarkan hasil wawancara dengan ketua MGMP matapelajaran Matematika Kabupaten Trenggalek diperoleh informasi banyak banyak guru-guru SMA Kabupaten Trenggalek yang belum banyak memanfaatkan teknologi dalam pembelajaran. Kurangnya integrasi teknologi dalam pembelajaran menyebabkan layanan guru kepada siswa dinilai kurang maksimal. Padahal penggunaan teknologi dalam pembelajaran mampu mengatasi masalah dalam proses belajar mengajar (Nurmansyah, 2017). Sebagai contoh, penggunaan software GeoGebra dapat meningkatkan pemahaman siswa dalam mempelajari konsep matematika (Nasution, 2015, 2016, 2018; Widyastuti, 2016). Dengan adanya alat bantu berupa media pembelajaran siswa dapat melakukan simulasi, mendapatkan ilustrasi dan visualisasi suatu objek dengan jelas. Hal ini berdampak pada pemahaman siswa tentang suatu konsep menjadi lebih baik dengan adanya media pembelajaran (Djamarah, 2010). 
Berdasarkan latar belakang di atas, beberapa dosen Jurusan Matematika mengadakan pengabdian kepada masyarakat berupa Workshop Media Pembelajaran Matematika Berbasis ICT MGMP Matematika SMA Kabupaten Trenggalek. Workshop ini bertujuan untuk memberikan dasar dan wawasan tentang pembuatan media pembelajaran matematika menggunakan software GeoGebra. Manfaat dari workshop ini diharapkan: (1) guru matematika SMA kabupaten Trenggalek mengenal software GeoGebra dan dapat melakukan instalasi GeoGebra, (2) guru matematika SMA kabupaten Trenggalek dapat menggunakan GeoGebra, dan (3) guru matematika SMA kabupaten Trenggalek dapat membuat media pembelajaran matematika menggunakan GeoGebra.

GeoGebra adalah kependekan dari kata Geometry and Algebra. Berdasarkan namanya, GeoGebra merupakan software matematika yang dikhususkan untuk masalah masalah geometri dan aljabar (Hohenwarter, 2008). GeoGebra dibuat pada tahun 2001 oleh Markus Hohenwarter ketika menyelesaikan tesis pada program master di University of Salzburg, Austria. Hohenwarter merancang GeoGebra dengan tujuan untuk pendidikan. Oleh karena itu GeoGebra dapat membantu para guru dan siswa untuk melakukan eksperimen, orientasi masalah dan penelitian bidang geometri baik di rumah maupun di sekolah. GeoGebra memiliki beragam fitur yang dapat digunakan untuk mengonstruksi gambar geometri. GeoGebra juga memilikii kemampuan aljabar untuk menyelesaikan masalah yang berhubungan dengan fungsi tertentu. Visualisasi objek geometri dan grafik fungsi dapat disajikan dengan GeoGebra. Objek yang divisualisasi oleh GeoGebra tidak terbatas pada objek dua dimensi saja, GeoGebra juga dapat memvisualisasi objek tiga dimensi.

\section{METODE}

Kegiatan pengabdian kepada masyarakat ini dikemas dalam bentuk workshop pembuatan media pembelajaran menggunakan GeoGebra. Workshop ini diikuti oleh 49 guru matematika SMA yang menjadi wakil dari sekolah sekolah di SMA Kabupaten Trenggalek. Materi yang disajikan dalam workshop ini adalah: (1) insyalasi software GeoGebra, (2) mengenal area kerja GeoGebra, (3) tools pada GeoGebra, (4) membuat objek menggunakan GeoGebra, (5) penggunaan slider, dan (6) dasar animasi pada GeoGebra.

Workshop dilaksanakan selama dua hari, $5-6$ Oktober 2019. Dalam pelaksanaannya, kegiatan workhsop ini dibantu oleh dua mahasiswa dan satu alumni Jurusan Matematika FMIPA Universitas Negeri Malang. Kegiatan workshop dilakukan dengan mekanisme sebagai berikut: (1) menyampaikan manfaat penggunaan GeoGebra dalam pembelajaran matematika, (2) menyampaikan teori tentang GeoGebra, (3) praktik software GeoGebra, (4) merancang media pembelajaran menggunakan GeoGebra, dan (5) evaluasi. Diagram alur kegiatan workshop disajikan pada Gambar 1. 


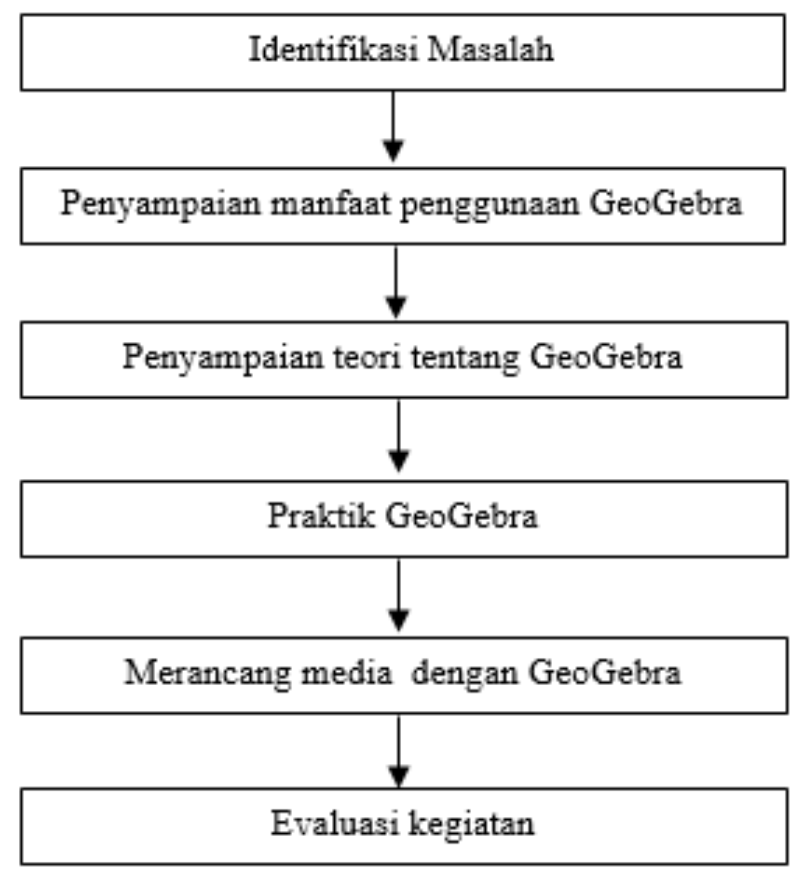

Gambar 1. Diagram Alur kegiatan Workshop

\section{HASIL DAN PEMBAHASAN}

Kegiatan workshop diawali dengan pembukaan. Dalam kegiatan pembukaan disampaikan pengantar dari Pembina MGMP Kabupaten Trenggalek dan ketua tim pengabdian kepada masyarakat Universitas Negeri Malang. Setelah pembukaan, dilaksanakan kegiatan inti, yaitu workshop pembuatan media menggunakan GeoGebra. Selama kegiatan workshop, peserta menggunakan laptop masing masing untuk mengikuti kegiatan. Kegiatan teori disampaikan lebih dahulu kemudian diikuti kegiatan praktik. Dalam kegiatan praktik, peserta dapat melakukan diskusi dengan peserta lain. Disela sela kegiatan, peserta yang dapat menyelesaikan suatu tugas tertentu akan mendapatkan doorprize.

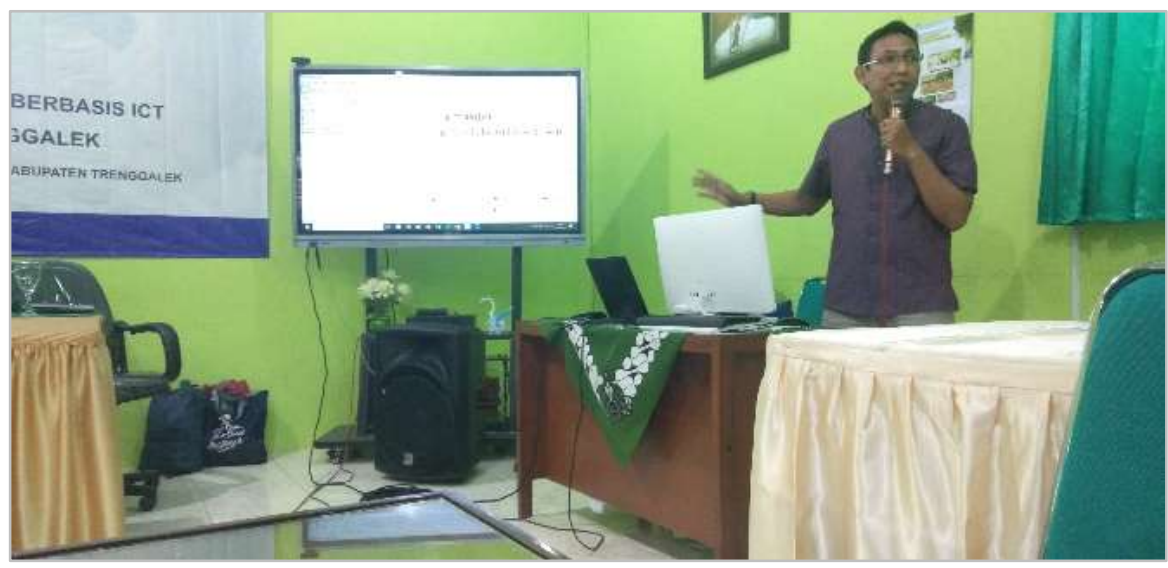

Gambar 2. Sesi penyampaian teori GeoGebra 


\section{Sekilas Tentang GeoGebra}

Lembar kerja GeoGebra dibagi dalam beberapa bagian. Bagian ini dapat diubah sesuai dengan kebutuhan. Secara default, bagian utama dari lembar kerja GeoGebra adalah toolbar, algebra view, graphics view, dan input bar. Lembar kerja GeoGebra disajikan pada Gambar 3. Bagian toolbar berisi tool-tool berupa icon yang digunakan untuk membuat objek GeoGebra. Bagian algebra view digunakan untuk tampilan aljabar dari objek GeoGebra, baik itu objek yang dibuat dari tools atau perintah GeoGebra. Bagian aljabar merupakan bagian yang penting, karena dapat memberikan informasi dari objek yang dibuat. Graphics View merupakan bagian yang digunakan untuk menampilkan objek GeoGebra. Graphics View merupakan visualisasi dari tools atau perintah GeoGebra. Objek yang ditampilkan pada Graphics View merupakan objek dimensi dua. Untuk objek dimensi tiga ditampilkan pada graphics 3D dengan mengaktifkan Graphics $3 D$ terlebih dahulu melalui menu view - 3D graphics. Bagian input bar digunakan untuk memasukkan perintah GeoGebra.

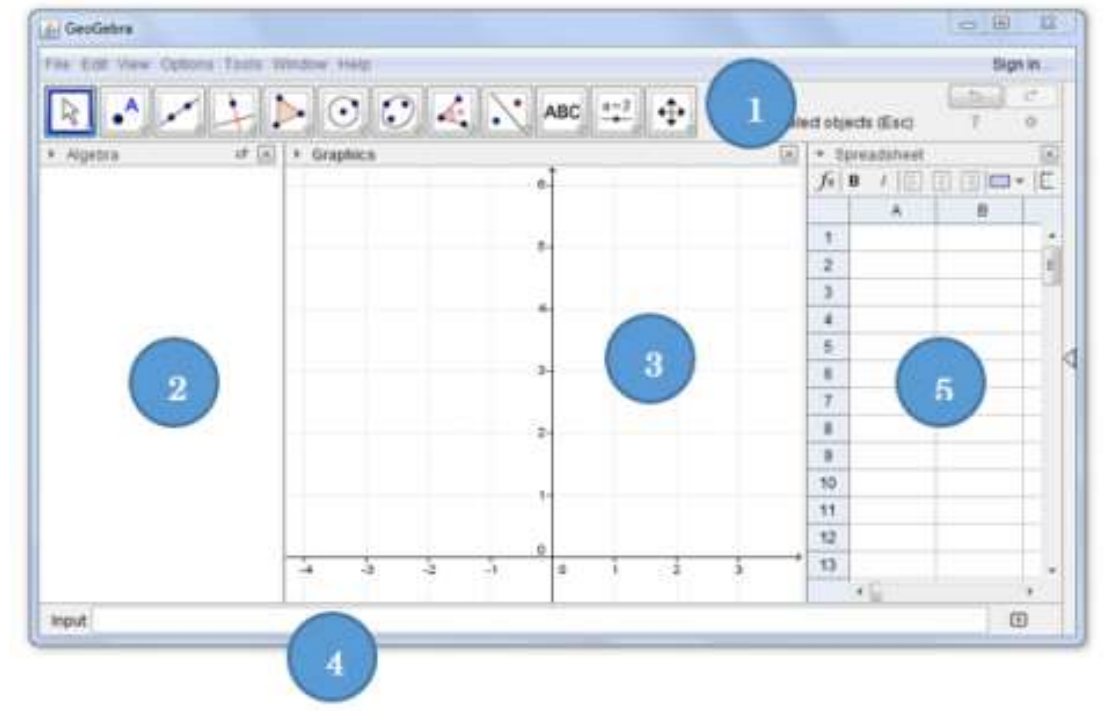

Gambar 3. Lembar kerja GeoGebra

Keterangan : 1. Toolbar, 2. Algebra View, 3. Graphics View, 4. Input Bar, 5. Spreedsheet View

\section{Media Pembelajaran yang Dibuat}

Produk media pembelajaran yang dibuat peserta selama workshop adalah: (1) Animasi grafik fungsi sinus, kosinus, dan tangen, (2) konsep integral tentu, (3) Animasi logika And dan Or, dan (4) Animasi irisan kerucut. Sebelum membuat media, terlebih dahulu dijelaskan analisis pendahuluan. Analisis pendahuluan bertujuan untuk membuat gambaran tentang media yang akan dibuat dan tools apa saja yang dibutuhkan. Setelah dilakukan analisis pendahuluan, peserta dipandu untuk menyusun media.

Media animasi grafik fungsi trigonometri menyajikan visualisasi dari grafik fungsi trigonometri $f(x)=\sin x, f(x)=\cos x$ dan $f(x)=\tan x$ dengan domain $\left[0^{\circ}, 360^{\circ}\right]$. Media ini digunakan untuk membelajarkan materi grafik fungsi trigonometri pada siswa SM. Tools yang digunakan untuk membuat ini adalah slider, button, dan checkbox. Tampilan media grafik fungsi trigonometri disajikan pada Gambar 4. 


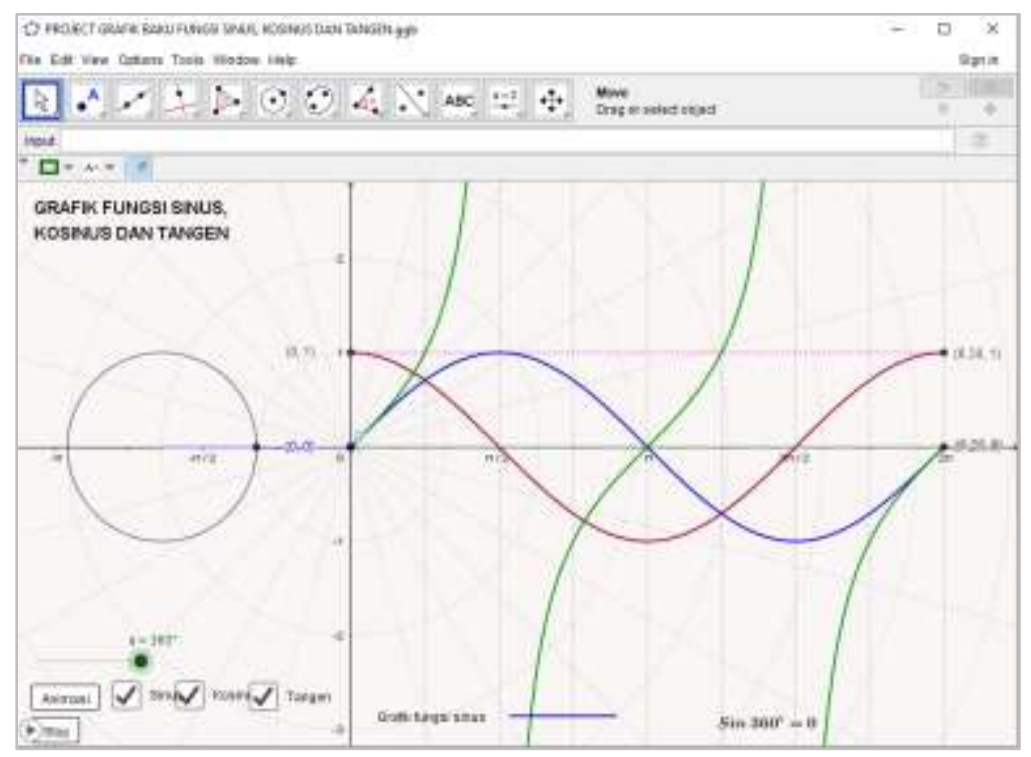

Gambar 4. Animasi grafik fungsi Trigonometri

Media kedua yang dibuat adalah animasi konsep integral tentu. Media ini dapat digunakan untuk membelajarkan konsep integral tentu menggunakan definisi integral Riemann pada siswa SMA. Siswa dapat memilih beberapa metode pembagian partisi seperti menggunakan poligon dalam, poligon luar, dan trapezoid. Siswa dapat mengatur jumlah partisi untuk mendekati luas daerah dengan cara menggeser slider. Tools yang digunakan untuk membuat media ini adalah slider, text, function, dan perintah sum yang diinputkan di input bar. Tampilan media animasi integral tentu disajikan pada Gambar 5.

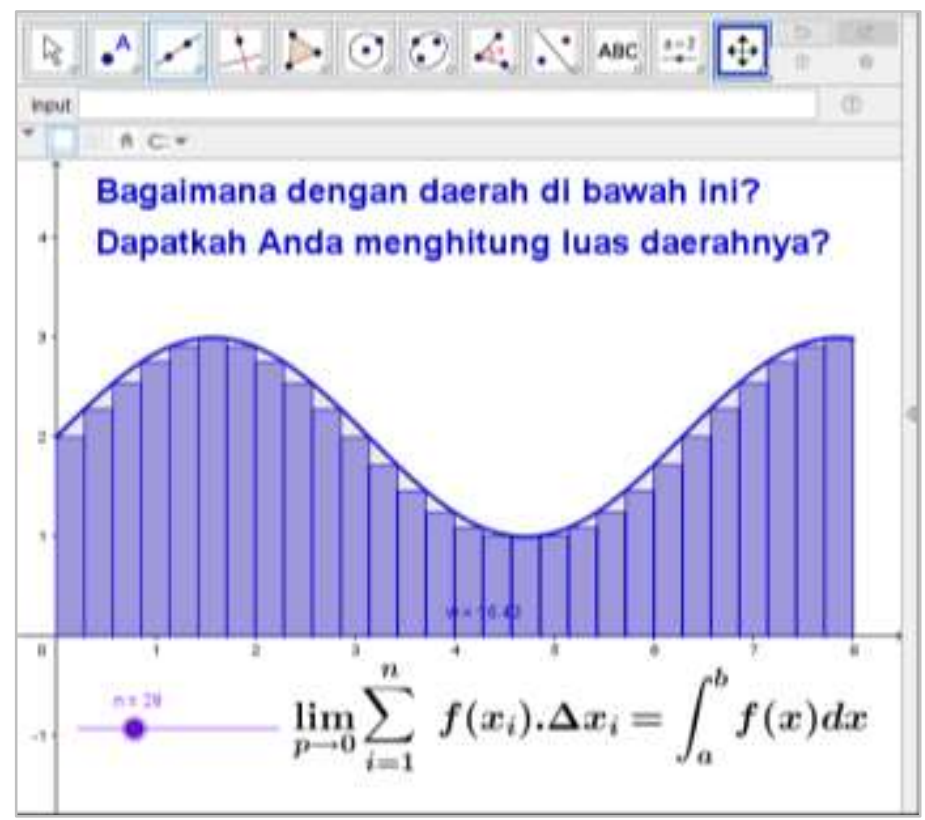

Gambar 5. Animasi integral tentu dengan GeoGebra

Media ketiga yang dibuat adalah animasi rangkaian seri dan paralel untuk menjelaskan konsep konjungsi dan disjungi pada materi logika matematika. Melalui media ini, siswa diharapkan siswa dapat membuat/menemukan konsep konjungsi dan 
disjungsi pada logika matematika serta dapat membuat tabel kebenarannya. Tampilan media disajikan pada Gambar 6.

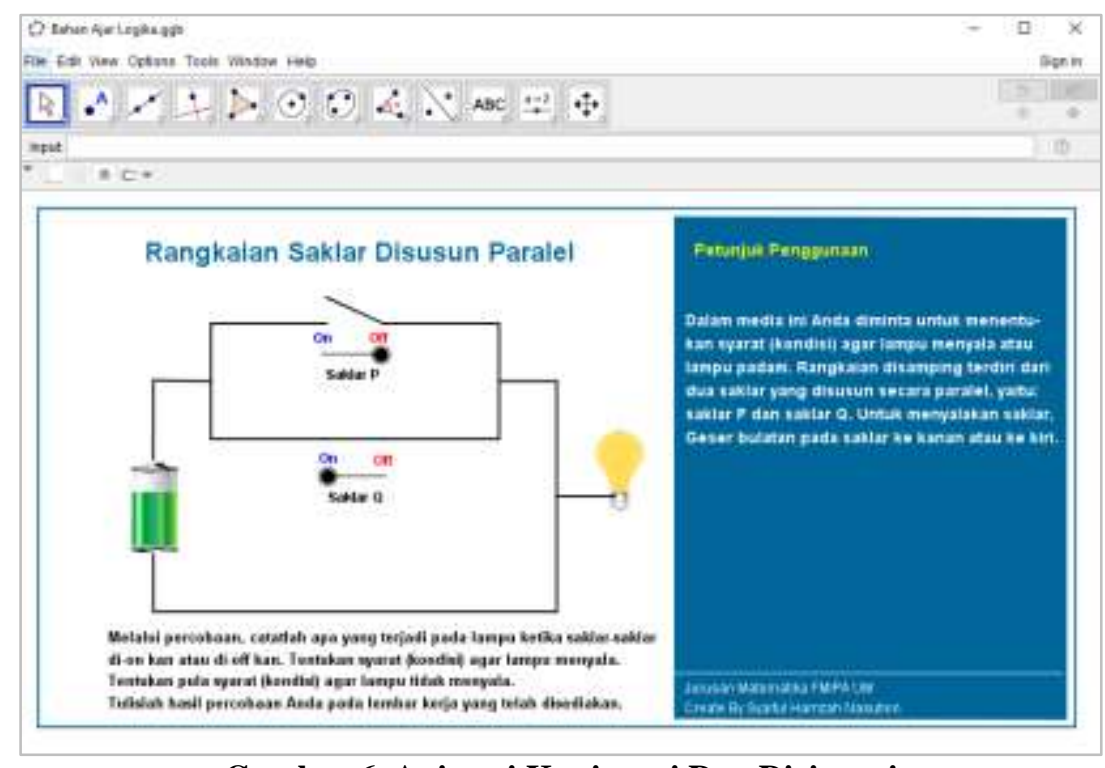

Gambar 6. Animasi Konjungsi Dan Disjungsi

Media terakhir yang dibuat adalah animasi irisan kerucut. Media ini dapat digunakan untuk memberikan visualisasi kerucut yang diiris oleh bidang datar. Media ini dapat digunakan siswa dalam belajar materi irisan kerucut. Media irisan kerucut ini menggunakan tampilan 3D. Siswa dapat menggeser dan merotasikan bidang pengiris serta dapat menentukan ukuran kerucut yang dibuat. Irisan kerucut divisualisasikan dengan baik melalui GeoGebra. Tampilan media animasi irisan kerucut disajikan pada Gambar 7.

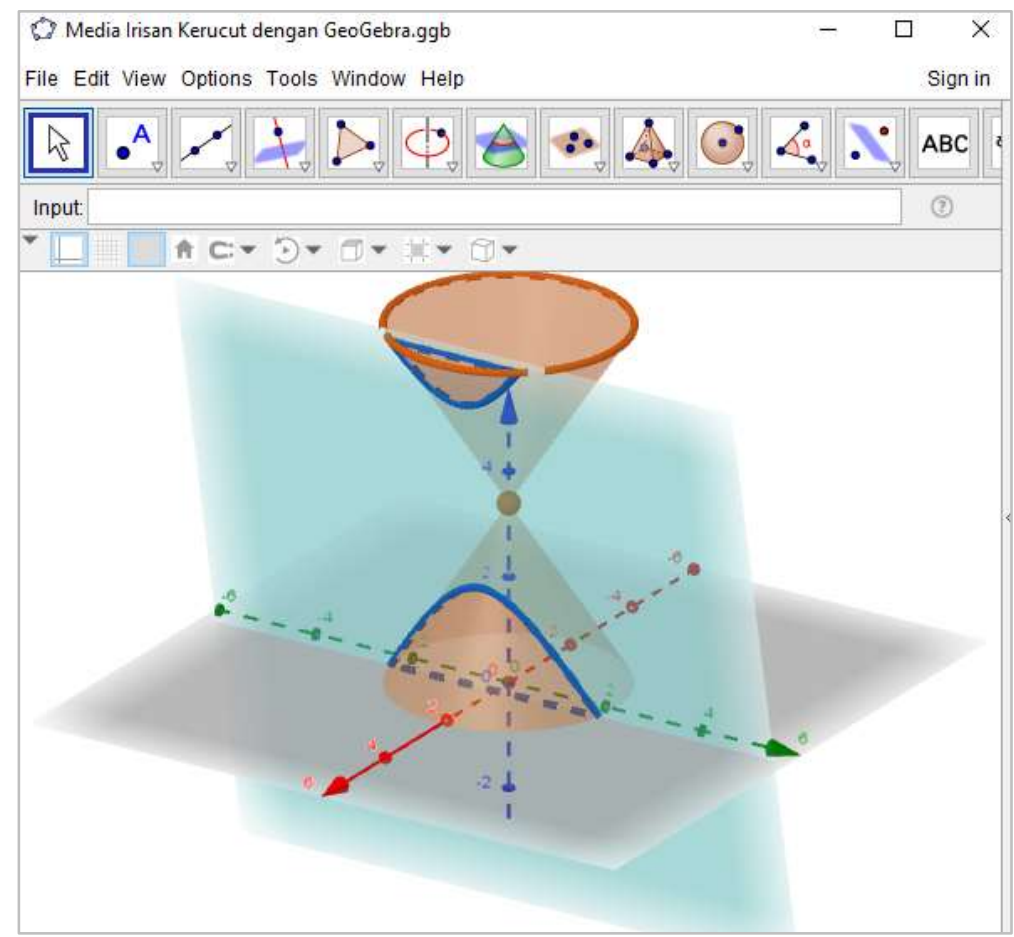

Gambar 7. Animasi Irisan Kerucut 
Setelah penyampaian materi dan praktik software GeoGebra secara tatap muka selesai dilaksanakan, dilakukan kegiatan pendampingan penyusunan media pembelajaran matematika secara online. Pendampingan ini bertujuan untuk memberi saran dan bantuan teknis dalam menyelesaikan tugas akhir yang diberikan pada saat workshop. Tugas akhir yang diberikan adalah menyusun media pembelajaran matematika menggunakan GeoGebra. Tugas ini dikerjakan secara kelompok dengan maksimal 3 anggota dalam satu kelompok. Selama pendampingan online peserta diperkenankan untuk tanya jawab terkait dengan penyelesaian tugas.

\section{KESIMPULAN DAN SARAN}

Berdasarkan hasil pelaksanaan pengabdian kepada masyarakat yang dikemas dalam workshop media pembelajaran matematika berbasis ICT MGMP Matematika SMA Kabupaten Trenggalek dapat disimpulkan hal-hal sebagai berikut:

1. Kegiatan workshop ini membantu guru Matematika SMA Kabupaten Probolinggo dalam menyusun media pembelajaran matematika menggunakan GeoGebra.

2. Guru Matematika SMA Kabupaten Trenggalek mengenal software GeoGebra dan dapat melakukan instalasi GeoGebra.

3. Guru Natenatika SMA Kabupaten Trengglek

\section{UCAPAN TERIMA KASIH}

Ucapan terima kasih kami sampaikan kepada Lembaga Penelitian dan Pengabdian kepada Masyarakat Universitas Negeri Malang dan Islamic Development Bank yang telah mendanai pengabdian kepada masyarakat ini.

\section{DAFTAR PUSTAKA}

Djamarah, S., \& Zain, A. 2010. Strategi Belajar Mengajar. Jakarta: PT Rineka Cipta.

Hohenwarter, et al. 2008. Teaching and Learning Calculus With Free Dyamic Mathematics Software GeoGebra.

Nasution, Syaiful Hamzah. 2015. Mengembangkan Media Pembelajaran Komputer pada Kelas Matematika. Prosiding Seminar Nasional Matematika dan Pembelajarannya, hal $712-721$.

Nasution, Syaiful Hamzah. 2016. Model Pembelajaran Kooperatif Menggunakan GeoGebra pada Matakuliah Matematika Dasar II. Jurnal Pembelajaran Matematika Tahun III Nomor 2.

Nasution, Syaiful Hamzah. 2018. Pentingnya Literasi Teknologi Bagi Mahasiswa Calon Guru Matematika. Jurnal Kajian Pembelajaran Matematika, Vol. 2, No. 1, hal 14 18.

Nurmansyah, Dimas Proyoga., \& Nasution, Syaiful Hamzah. 2017. Pengembangan Media Pembelajaran Berbasis Android Menggunakan Sofware Construct 2 pada Materi Persamaan Garis Lurus. Prosiding Seminar Nasional Matematika dan Pembelajarannya, hal $1071-1078$.

Widyastuti, Ratna. 2016. Workshop Penerapan Software GeoGebra sebagai Media Pembelajaran Matematika untuk Guru SMA Negeri 7 Kediri. Jurnal Ilmu Pengetahuan dan Teknologi Terintegrasi, Vol. 1 No. 2, hal 25 - 29. 